\title{
Una guía para el manejo clínico de la infección por SARS-CoV-2 acorde con la realidad de México
}

\section{Guidelines for SARS-CoV-2 infection clinical management according to Mexico's reality}

\author{
René A. Flores-Franco*
}

Instituto Mexicano de Seguro Social, Hospital General Regional de Zona 1, Servicio de Medicina Interna, Chihuahua, México

Leí con interés el artículo sobre las guías para el manejo clínico de la infección por SARS-CoV-2, en el cual se exponen razonablemente bien las opciones terapéuticas en pacientes infectados por dicho virus, ${ }^{1}$ que se formularon considerando su aplicabilidad en la práctica diaria, tanto institucional como en el ámbito privado. A más de un año de iniciada la pandemia en el Instituto Mexicano del Seguro Social, no se dispone de antivirales con efectividad clínica comprobada y solo se cuenta con esteroides sistémicos para combatir la tormenta de citocinas. En la práctica privada, las aseguradoras no cubren los gastos generados por el uso de remdesivir, baricitinib ni tocilizumab, considerados como medicamentos en fase experimental.

A falta de un soporte científico se ha recurrido al soporte filosófico por ejemplo, algunos consideran que se está ante un escenario emocional y socialmente en riesgo para una objetividad científica y médica en la búsqueda de nuevas alternativas terapéuticas para auxiliar a los pacientes. ${ }^{2}$ No obstante, ¿no podría ser ese escenario un obstáculo epistemológicamente paralizante para la búsqueda de nuevos tratamientos? La situación de crisis puede llevar a callejones obscuros, uno de los cuales puede ser la inacción o la omisión culpable.

Ahora bien, no han sido pocos los filósofos de la ciencia que han cuestionado la objetividad científica como un absoluto y más si se entiende esa objetividad como un desprecio de la experiencia. Ya Thomas $\mathrm{S}$. Khun, en La estructura de las revoluciones científicas, dejó claro cómo determinados paradigmas se imponen a la comunidad científica y generan lo que se llama una "ciencia normal", que se resiste sistemáticamente a cualquier posibilidad o cualquier hipótesis fuera del esquema socialmente aceptado por la misma comunidad científica, la mayor parte de las veces legitimado por investigaciones con limitantes.

El conocimiento científico no surge ni proviene de una región etérea e intangible como el mundo platónico de las ideas. Su punto de partida es la experiencia. Tanto no existe justificación ética para especular con los pacientes, ni tampoco justificación ética para no considerar alternativas potencialmente útiles. Al final de cuentas, con justicia y buena lógica, las inacciones y omisiones también son acciones. Se peca también de omisión. $Y$ aunque no pueden anticiparse, sí pueden constatarse cuando ya han sucedido y más de 200000 muertos en este país deja muy claro los posibles alcances de algunas de las inacciones.

Con todo lo anterior, bajo el contexto de nuestra realidad en la práctica profesional, habría que brindar una oportunidad a medicamentos aún no explorados "científicamente", pero potencialmente benéficos en el tratamiento de pacientes infectados de SARS-CoV-2. Medicamentos de mejor acceso, bajo costo, efectivos y que, bien indicados, tengan un perfil de seguridad aceptable. Las carencias institucionales y la falta de soporte por las aseguradoras han orillado a buscar urgentemente alternativas en pacientes con resistencia a los esteroides sistémicos, sobre todo medicamentos con actividad inmunomoduladora con una efectividad objetivamente demostrable en los parámetros inflamatorios
Correspondencia:

${ }^{*}$ René A. Flores-Franco

E-mail: rflores99@prontomail.com
Gac Med Mex. 2021;157:467-468

Disponible en PubMed

www.gacetamedicademexico.com

0016-3813/@ 2021 Academia Nacional de Medicina de México, A.C. Publicado por Permanyer. Este es un artículo open access bajo la licencia CC BY-NC-ND (http://creativecommons.org/licenses/by-nc-nd/4.0/). 
en sangre periférica: cuenta linfocitaria, niveles de proteína C reactiva e interleucina 6 .

El metotrexate ha reunido dichas expectativas y su utilidad ha sido sugerida desde el inicio de la pandemia. ${ }^{3}$ Partiendo de que en otras enfermedades autoinmunes que se tratan con metotrexate no se incrementa la probabilidad de hospitalización o la mortalidad de infectarse de SARS-CoV-2, pudiera concluirse que su uso no complica el curso de la enfermedad. A bajas dosis, el metrotrexate bloquea la vía intracelular Jak/ Stat implicada en la transducción de información generada por diversas citocinas y controla respuestas inmunitarias e inflamatorias.
Bajo un contexto de incertidumbre científica y presiones externas, el clínico debe tomar decisiones en México en cuanto al tratamiento del paciente infectado de SARS-CoV-2 que difícilmente serían incluidas en alguna guía clínica.

\section{Bibliografía}

1. García-Álvarez JL, García-Vigil JL. Guidelines for clinical management of SARS-CoV-2 infection. Gac Med Mex. 2020;156:576-583.

2. Martínez-Michel O, Romero-Thirión II. El uso de tocilizumab en pacientes con COVID-19. Consideraciones metodológicas y éticas. Neumol Cir Torax. 2021;80:6-8.

3. Rajaiah R, Abhilasha KV, Shekar MA, Vogel SN, Vishwanath BS. Evaluation of mechanisms of action of re-purposed drugs for treatment of COVID-19. Cell Immunol. 2020;358:104240. 